\title{
COVID-19: Lymphocyte Subpopulations Monitoring in Critically Ill Patients
}

\author{
Amra Ziadi', Abdelhamid Hachimi2*, Raja Hazime ${ }^{3}$, Imane Brahim ${ }^{3}$, Brahim Admou ${ }^{3}$, \\ Fouzia Douirek¹, Ahmed R. El Adib ${ }^{4}$, Said Younous ${ }^{4}$, Abdenasser M. Samkaoui1
}

${ }^{1}$ Polyvalent Intensive Care Unit, Arrazi Hospital, Mohammed VI ${ }^{\text {th }}$ University Centre, Cadi Ayyad University, Marrakech, Morocco ${ }^{2}$ Medical Intensive Care Unit, Arrazi Hospital, Mohammed VI ${ }^{\text {th }}$ University Centre, Cadi Ayyad University, Marrakech, Morocco ${ }^{3}$ Laboratory of Immunology, Centre of Clinical Research, Mohammed VI ${ }^{\text {th }}$ University Centre, Cadi Ayyad University, Marrakech, Morocco

${ }^{4}$ Polyvalent Intensive Care Unit, Child and Mother Hospital, Mohammed VI ${ }^{\text {th }}$ University Centre, Cadi Ayyad University, Marrakech, Morocco

Email: *abdelhachimi@gmail.com

How to cite this paper: Ziadi, A., Hachimi, A., Hazime, R., Brahim, I., Admou, B., Douirek, F., El Adib, A.R., Younous, S. and Samkaoui, A.M. (2020) COVID-19: Lymphocyte Subpopulations Monitoring in Critically Ill Patients. International Journal of Clinical Medicine, 11, 465-473.

https://doi.org/10.4236/ijcm.2020.118039

Received: July 5, 2020

Accepted: August 4, 2020

Published: August 7, 2020

Copyright $\odot 2020$ by author(s) and Scientific Research Publishing Inc. This work is licensed under the Creative Commons Attribution International License (CC BY 4.0).

http://creativecommons.org/licenses/by/4.0/

(c) (i) Open Access

\begin{abstract}
Background: The alteration of lymphocyte subpopulations can help to predict the severity and the prognosis of severe Coronavirus disease 2019 (COVID-19). Our goal was to describe the kinetics of lymphocyte subsets, and their impact on the severity and mortality in critically ill COVID-19 patients. Methods: We collected demographic data, comorbidities, clinical signs on admission, laboratory findings on admission then a follow-up during hospitalization. Lymphocyte subsets including CD3+ T cells, CD4+ T cells, CD8+ T cells, B cells, and natural killer (NK) cells were counted by flow cytometer. Results: On admission, we observed lymphopenia in $57 \%$ of cases, decreased CD3+ T cells in $76 \%$ of cases, decreased CD4+ T cells in $81 \%$ of cases, decreased CD8+ T cells in $62 \%$ of cases, decreased B cells in $52 \%$ of cases, and decreased natural killer (NK) cells in 33\% of cases. After treatment, decreased CD3+ T cells, decreased CD4+ T cells, decreased CD8 $+\mathrm{T}$ cells, and decreased natural killer cells were predictor factors of mortality, in the univariable analysis. Conclusion: $\mathrm{CD} 3+\mathrm{T}$ cells, CD4 $\mathrm{T}$ cells, $\mathrm{CD} 8+\mathrm{T}$ cells, and natural killer cells were predictor factors of severity, ICU mortality, and also a useful tool for predicting disease progression.
\end{abstract}

\section{Keywords}

SARS-CoV-2, Coronavirus Disease 2019, Lymphocyte Subsets, Critical Care Outcomes 


\section{Introduction}

In December 2019, a new disease due to SARS-CoV-2 infection appeared in China. A few weeks later, it spreads and becomes a pandemic; about 6,931,000 cases have been infected globally with 400,857 (5.8\%) deaths, as of June 8, 2020 [1]. The pathophysiology of this infection remains not fully clarified. Although, it has been observed that SARS-Cov-2 is responsible for a reactive inflammatory storm as a result of an exaggerated host immune system response, with deleterious effects on multiple organs; firstly, in the most of the cases, it affects pulmonary tract, then, the others systems including cardiovascular, gastrointestinal, neurological, hematopoietic and immune system [2] [3] [4].

Even though $\mathrm{T}$ lymphocytes and natural killer cells are essential to control viral infections, lymphopenia is a frequent hematological disorder in serious COVID-19 patients [5] [6] [7]. This abnormality might be explained by firstly, the virus may directly affect lymphocytes [8], because of the expression of angiotensin-converting enzyme- 2 on the surface of lymphocytes [9] [10]. Secondly, their inhibition by metabolic disorders (i.e. lactic acidosis) [11]. Thirdly, pro-inflammatory cytokines including tumor necrosis factor (TNF) $\alpha$, and interleukin (IL)-6, could provoke lymphocyte deficit, and fourthly, the virus might engender lymphatic organs damage such as thymus and spleen [12]. Thus, the occurrence rate was between $44.5 \%$ [13], 67\% [14], and 92.6\%, (15) of critically ill COVID-19 cases, because of they adopted different definitions: lymphocytes $<500 / \mathrm{mm}^{3}$ [13], lymphocytes $<1000 \mathrm{~mm}^{3}$ [14], or lymphocytes $<1500 \mathrm{~mm}^{3}$ [15]. Moreover, lymphocyte subpopulations decreased and predicted the severity and the prognosis of severe COVID-19 [16] [17]. Herein, our goal was to describe the kinetics of lymphocyte subsets, and their impact on the severity and mortality in critically ill COVID-19 patients.

\section{Methods}

For this prospective single-center study, we included all adult patients with confirmed COVID-19 infection by a positive reverse-transcriptase-polymerasechain-reaction (RT-PCR) assay of a nasopharyngeal swab, admitted in the intensive care unit (ICU) of the Mohammed VI ${ }^{\text {th }}$ University Centre of the Marrakech region, Morocco, from Mach 19, 2020, to May 15, 2020.

Critically ill patients were defined as admitted in the ICU because they required mechanical ventilation or more than eight liters per minute of oxygen to maintain pulse oxygen saturation $\left(\mathrm{SpO}_{2}\right)>90 \%$ or had a respiratory rate of more than 40 breaths per minute.

We collected demographic data, clinical signs, laboratory findings on admission then a follow-up during hospitalization (lymphocytes, D-dimer, ferritin, lactate dehydrogenase ( $\mathrm{LDH}$ ), C-reactive protein, procalcitonin, $\mathrm{PaO}_{2}: \mathrm{FiO}_{2}$ ), chest CT scan if available, outcomes, time from onset of the first symptom to ICU admission, Charlson Comorbidity Index [18] and sequential organ failure assess- 
ment (SOFA) scores [19]. CD3+ T cells, CD4+ T cells, CD8+ T cells, B cells, and natural killer (NK) cells were counted by flow cytometer. All tests were performed at the discretion of the treating physician.

We expressed continuous variables as medians and interquartile (IQR) ranges or means (standard deviations (SD)), as appropriate. Categorical variables were described using percentages and compared using the $\chi^{2}$ test, although Fisher exact test was used when the data were sparse. We performed a univariable analysis to evaluate the risk factors of mortality. The analysis was processed by SPSS 10.0 for Windows (SPSS, Chicago, IL, USA). A p-value of less than 0.05 was considered statistically significant.

Informed consent was waived due to the emergency of the disease, and researchers analyzed only anonymized data. All research was conducted following the national guidelines and regulations.

\section{Results}

Of 1618 COVID-19 patients hospitalized in our university center, 55 patients (3.4\%) were admitted to the ICU. We list the basic, clinical characteristics, biological and radiological findings in Table 1. The mean age was 59 (16.5) years; $74.5 \%$ were men. Among all the patients, $84 \%$ had chronic medical conditions. The frequent symptoms were dyspnoea (85\%), and cough (80\%). The median length from the onset of symptoms to ICU admission was 7 (6 - 8) days. The median SOFA score on admission was 5 (4 - 17). On admission, lymphopenia was common (76\%) with a median of $980 / \mathrm{mm}^{3}$, the median LDH was $560 \mathrm{IU} / \mathrm{L}$, the median D-dimer was $2975 \mathrm{mg} / \mathrm{L}$, the median ferritin was $1135 \mathrm{ng} / \mathrm{mL}$. The chest CT scan showed bilateral ground-glass opacification $>50 \%$ in $74 \%$ of cases.

Among the 55 patients, we analyzed the lymphocyte subsets from 21 patients. On admission, we observed lymphopenia in $57 \%$ of cases, decreased CD3+ $\mathrm{T}$ cells in $76 \%$ of cases, decreased CD $4+$ T cells in $81 \%$ of cases, decreased CD $8+$ $\mathrm{T}$ cells in $62 \%$ of cases, decreased B cells in $52 \%$ of cases, and decreased natural killer (NK) cells in $33 \%$ of cases. In these 21 patients, $71.4 \%(15 / 21)$ received chloroquine/hydroxychloroquine plus azithromycin, and 4.8\% (1/21) treated with lopinavir/ritonavir. The monitoring of the lymphocyte subpopulation counts was reported in Figure 1. Effectively, after treatment, only 2/9 non-survivor patients improved their CD3+ T cells versus 10/12 survivor patients. Besides, regarding the CD4+ T cells, 11/12 survivor patients presented a normal count versus $1 / 9$ non-survivor patients. The mortality rate was $43.6 \%$ of cases (24 patients). On admission, none of the decreased lymphocyte subsets was associated with mortality. However, after treatment, decreased CD3+ T cells (78\% vs 17\%; $\mathrm{p}=0.009)$, decreased CD4+ T cells (90\% vs 8\%; $\mathrm{p}<0.001)$, decreased CD8+ T cells $(90 \%$ vs $8 \%$; $\mathrm{p}<0.001)$, and decreased natural killer cells $(67 \%$ vs $0 \%$; $=$ 0.002 ) were predictor factors of mortality, in the univariable analysis (Table 2). 
Table 1. Basic and clinical characteristics, laboratory data and chest CT scan findings of all patients.

\begin{tabular}{|c|c|}
\hline Characteristics & All patients $(\mathrm{N}=55)$ \\
\hline Mean age (SD) (year) & $59(16.5)$ \\
\hline \multicolumn{2}{|l|}{$\operatorname{Sex}(\%)$} \\
\hline Male & 74.5 \\
\hline Female & 25.5 \\
\hline Comorbidities (\%) & 84 \\
\hline Hypertension & 42 \\
\hline Diabetes & 34 \\
\hline Coronary heart disease & 11 \\
\hline Chronic kidney disease & 9 \\
\hline Chronic obstructive pulmonary disease & 4 \\
\hline Cerebrovascular disease & 4 \\
\hline Cancer & 4 \\
\hline Asthma & 2 \\
\hline Cirrhosis & 2 \\
\hline Connective tissue disease & 2 \\
\hline Smoking & 16 \\
\hline Alcoholism & 4 \\
\hline Others & 11 \\
\hline Charlson Comorbidity Index score, median (IQR) & $3(2-5)$ \\
\hline $\begin{array}{l}\text { Length from the onset of symptoms to ICU admission, median (IQR) } \\
\text { (day) }\end{array}$ & $7(6-8)$ \\
\hline \multicolumn{2}{|l|}{ Symptoms (\%) } \\
\hline Dyspnea & 85 \\
\hline Cough & 80 \\
\hline Respiratory struggle & 54 \\
\hline Fever & 26 \\
\hline Digestive signs & 26 \\
\hline Agitation & 22 \\
\hline \multicolumn{2}{|l|}{ SOFA score } \\
\hline On admission, median (IQR) & $5(4-17)$ \\
\hline Highest score during the first three days, median (IQR) & $10(5-16.5)$ \\
\hline On day 7 , median (IQR) & $11(4-16.75)$ \\
\hline
\end{tabular}




\section{Continued}

\section{Laboratory data}

On admission

Lymphocytes count, median (IQR) (per $\mathrm{mm}^{3}$ )

$980(565-1455)$

D-dimer, median (IQR) (mg/L)

$2975(1490-7112)$

Ferritin, median (IQR) (ng/mL)

$1135(547-2023)$

LDH, median (IQR) (IU/L)

$560(381-766)$

C-reactive protein, median (IQR) (mg/L)

$173(99-243)$

Procalcitonin, median (IQR) (ng/mL)

$0.31(0.13-0.71)$

$\mathrm{PaO}_{2}: \mathrm{FiO}_{2}$ ratio, median (IQR)

$86(70-130)$

During the first 3 days

Lowest lymphocytes count, median (IQR) (per $\mathrm{mm}^{3}$ )

$810(655-1035)$

Highest D-dimer level, median (IQR) (mg/L)

$3225(289-9992)$

Highest ferritin level, median (IQR) (ng/mL)

$1416(688-1940)$

Highest LDH level, median (IQR) (IU/L)

$560(381-766)$

Highest C-reactive protein level, median (IQR) (mg/L)

$175(111-253)$

Highest procalcitonin level, median (IQR) (ng/mL)

$2(0.38-3.85)$

Lowest $\mathrm{PaO}_{2}: \mathrm{FiO}_{2}$ ratio, median (IQR)

$86(70-130)$

On day 7

Lymphocytes count, median (IQR) (per $\mathrm{mm}^{3}$ )

$763(570-1540)$

D-dimer level, median (IQR) (mg/L)

$4045(2752$ - 9877)

Ferritin level, median (IQR) (ng/mL)

$1325(734-1940)$

LDH, median (IQR) (IU/L)

$402(271-507)$

C-reactive protein level, median (IQR) (mg/L)

$98(52-170)$

Procalcitonin level, median (IQR) (ng/mL)

$0,59(0.18-4.25)$

$\mathrm{PaO}_{2}: \mathrm{FiO}_{2}$ ratio, median (IQR)

$98(78-148)$

Chest CT scan (\%)

Ground glass opacification $<25 \%$

10

Ground glass opacification 25\% - 49\%

16

Ground glass opacification 50\% - 74\%

37

Ground glass opacification 75\% - 100\%

37

Pleural effusion

0

IQR, interquartile range. SOFA, sequential organ failure assessment. $\mathrm{LDH}$, lactate dehydrogenase. $\mathrm{PaO}_{2}: \mathrm{FiO}_{2}$, the ratio of the partial pressure of arterial oxygen to the fraction of inspired oxygen. 
Table 2. Predictor factors of mortality in univariable analysis.

\begin{tabular}{|c|c|c|c|c|c|c|}
\hline & \multicolumn{3}{|c|}{ Before treatment } & \multicolumn{3}{|c|}{ After treatment } \\
\hline & Non-survivors & Survivors & $\mathrm{p}$ & Non-survivors & Survivors & $\mathrm{p}$ \\
\hline Decreased CD3+ T cells (\%) & 89 & 68 & 0.3 & 78 & 17 & 0.009 \\
\hline Decreased CD4+ T cells $(\%)$ & 88 & 75 & 0.6 & 90 & 8 & $<0.001$ \\
\hline Decreased CD8+ T cells (\%) & 88 & 42 & 0.06 & 90 & 8 & $<0.001$ \\
\hline Decreased B cells (\%) & 56 & 50 & 0.9 & 11 & 0 & 0.4 \\
\hline Decreased natural killer cells (\%) & 34 & 33 & 0.9 & 67 & 0 & 0.002 \\
\hline
\end{tabular}
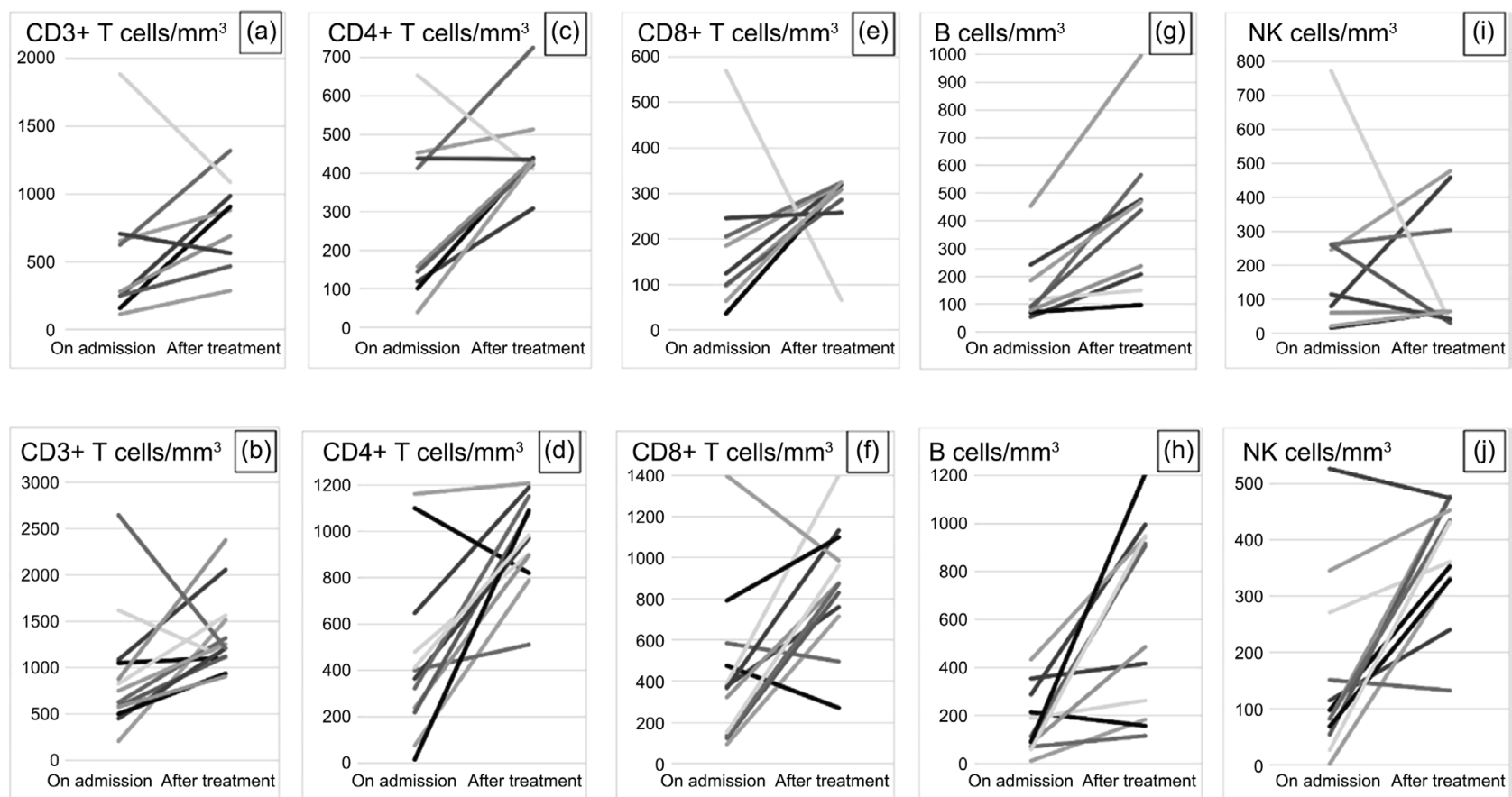

Figure 1. The kinetics of lymphocyte subpopulations (CD3+ T cells, CD4+ T cells, CD8+ T cells, B lymphocytes, and natural killer $(\mathrm{NK})$ ) between admission and after treatment in non-survivor patients ((a), (c), (e), (g), and (i)) and in survivor patients ((b), (d), $(\mathrm{f}),(\mathrm{h})$, and (j)).

\section{Discussion}

In our population, after treatment, decreased CD3+ $\mathrm{T}$ cells, decreased $\mathrm{CD} 4+\mathrm{T}$ cells, decreased CD8+ T cells, and decreased natural killer cells were predictor factors of mortality; further, a large proportion of patients recovered lymphocyte subpopulations in survivor cases. At the best of our knowledge, this is the first report of the monitoring lymphocyte subsets in a Moroccan cohort of critically ill COVID-19 patients.

These findings were in line with the publishing data. Wang et al. [20] declared the count alteration of total lymphocytes, CD4+ T cells, CD8+ T cells, B cells, and natural killer cells in COVID-19 patients; as well, the CD8+ cells was an independent marker of severity and efficacy of treatment. And accordingly to Sun et al. [21] who observed that total T lymphocytes, CD4+ T lymphocytes, CD8+ T 
lymphocytes, and NK cells decreased in un-discharged/died group at two weeks after treatment, compared with the discharged group. Additionally, CD4+ $\mathrm{T}$ cells and CD8+ T cells could help to evaluate the disease evolvement [22]. Besides, a recent meta-analysis concluded that lymphopenia was related to worsened outcomes [23].

This study has some limitations. The first concern was that our study was a single-centered study with only 55 severe patients, of whom only 21 patients who had lymphocytes subset counts. Secondly, we collected lymphocyte subset counts on admission in the intensive care unit, but some patients were initially hospitalized in a general ward for some days. Thirdly, the interpretation of our findings might be limited by the sample size. However, our ICU was the referral center in the region, thus we consider our study population is representative of cases diagnosed and treated in our region. Further studies through the country still needed.

\section{Conclusion}

CD3+ T cells, CD4+ T cells, CD8+ T cells, and natural killer cells were predictor factors of severity and ICU mortality. As well, they were a useful tool for predicting disease progression. Other larger sample studies are needed to validate risk factors and the lymphocyte threshold.

\section{Ethical Considerations}

Informed consent was waived due to the emergency of the disease, and researchers analyzed only anonymized data. All research was conducted following the national guidelines and regulations.

\section{Acknowledgements}

We thank the staff of the Laboratory of Immunology. We also greatly appreciate the efforts of healthcare workers in the Department of Critical Care and Anesthesia.

\section{Authors' Contributions}

A.Z., A.H., H.R., B.A., and A.M.S. designed the study; A.Z. and A.H. wrote and edited the paper; R.H., I.B., B.A., and A.R.E. discussed results, and edited the paper; F.D., Y.Z., H.C., and S.Y. discussed results and edited the paper.

\section{Funding}

This research was funded by all authors. No funding agency.

\section{Conflicts of Interest}

The authors declare no conflicts of interest regarding the publication of this paper. 


\section{References}

[1] World Health Organization (2020) Coronavirus Disease (COVID-19) [Internet]. https://www.who.int/docs/default-source/coronaviruse/situation-reports/20200608covid-19-sitrep-140.pdf?sfvrsn=2f310900 2

[2] Driggin, E., Madhavan, M.V., Bikdeli, B., Chuich, T., Laracy, J., Biondi-Zoccai, G., et al. (2020) Cardiovascular Considerations for Patients, Health Care Workers, and Health Systems during the COVID-19 Pandemic. Journal of the American College of Cardiology, 75, 2352-2371. https://doi.org/10.1016/j.jacc.2020.03.031

[3] Bangash, M.N., Patel, J. and Parekh, D. (2020) COVID-19 and the Liver: Little Cause for Concern. The Lancet Gastroenterology and Hepatology, 5, 529-530. https://doi.org/10.1016/S2468-1253(20)30084-4

[4] Mehta, P., McAuley, D.F., Brown, M., Sanchez, E., Tattersall, R.S. and Manson, J.J. (2020) COVID-19: Consider Cytokine Storm Syndromes and Immunosuppression. The Lancet, 395, 1033-1034. https://doi.org/10.1016/S0140-6736(20)30628-0

[5] Huang, C., Wang, Y., Li, X., Ren, L., Zhao, J., Hu, Y., et al. (2020) Clinical Features of Patients Infected with 2019 Novel Coronavirus in Wuhan, China. The Lancet, 395, 497-506. https://doi.org/10.1016/S0140-6736(20)30183-5

[6] Wang, D., Hu, B., Hu, C., Zhu, F., Liu, X., Zhang, J., et al. (2020) Clinical Characteristics of 138 Hospitalized Patients with 2019 Novel Coronavirus-Infected Pneumonia in Wuhan, China. JAMA, 323, 1061-1069.

https://doi.org/10.1001/jama.2020.1585

[7] Wu, C., Chen, X., Cai, Y., Xia, J., Zhou, X., Xu, S., et al. (2020) Risk Factors Associated with Acute Respiratory Distress Syndrome and Death in Patients with Coronavirus Disease 2019 Pneumonia in Wuhan, China. JAMA Internal Medicine, 180, e200994. https://doi.org/10.1001/jamainternmed.2020.0994

[8] Xu, H., Zhong, L., Deng, J., Peng, J., Dan, H., Zeng, X., et al. (2020) High Expression of ACE2 Receptor of 2019-nCoV on the Epithelial Cells of Oral Mucosa. International Journal of Oral Science, 12, Article No. 8. https://doi.org/10.1038/s41368-020-0074-x

[9] Zhang, H., Penninger, J.M., Li, Y., Zhong, N. and Slutsky, A.S. (2020) Angiotensin-Converting Enzyme 2 (ACE2) as a SARS-CoV-2 Receptor: Molecular Mechanisms and Potential Therapeutic Target. Intensive Care Medicine, 46, 586-590. https://doi.org/10.1007/s00134-020-05985-9

[10] Wan, Y., Shang, J., Graham, R., Baric, R.S. and Li, F. (2020) Receptor Recognition by the Novel Coronavirus from Wuhan: An Analysis Based on Decade-Long Structural Studies of SARS Coronavirus. Journal of Virology, 94, e00127-20. https://doi.org/10.1128/JVI.00127-20

[11] Fischer, K., Hoffmann, P., Voelkl, S., Meidenbauer, N., Ammer, J., Edinger, M., et al. (2007) Inhibitory Effect of Tumor Cell-Derived Lactic Acid on Human T Cells. Blood, 109, 3812-3819. https://doi.org/10.1182/blood-2006-07-035972

[12] Liao, Y.C., Liang, W.G., Chen, F.W., Hsu, J.H., Yang, J.J. and Chang, M.S. (2002) IL-19 Induces Production of IL- 6 and TNF- $\alpha$ and Results in Cell Apoptosis through TNF- $\alpha$. The Journal of Immunology, 169, 4288-4297. https://doi.org/10.4049/jimmunol.169.8.4288

[13] Fan, B.E., Chong, V.C.L., Chan, S.S.W., Lim, G.H., Lim, K.G.E., Tan, G.B., et al. (2020) Hematologic Parameters in Patients with COVID-19 Infection. American Journal of Hematology, 95, E131-E134. https://doi.org/10.1002/ajh.25774

[14] Arentz, M., Yim, E., Klaff, L., Lokhandwala, S., Riedo, F.X., Chong, M., et al. (2020) 
Characteristics and Outcomes of 21 Critically Ill Patients with COVID-19 in Washington State. JAMA Journal of the American Medical Association, 323, 1612-1614. https://doi.org/10.1001/jama.2020.4326

[15] Guan, W.J., Ni, Z.Y., Hu, Y., Liang, W.H., Ou, C.Q., He, J.X., et al. (2020) Clinical Characteristics of Coronavirus Disease 2019 in China. The New England Journal of Medicine, 382, 1708-1720. https://doi.org/10.1056/NEJMoa2002032

[16] D’Alessandro, M., Bennett, D., Montagnani, F., Cameli, P., Perrone, A., Bergantini, L., et al. (2020) Peripheral Lymphocyte Subset Monitoring in COVID19 Patients: A Prospective Italian Real-Life Case Series. Minerva Medica.

[17] Liu, Z., Long, W., Tu, M., Chen, S., Huang, Y., Wang, S., et al. (2020) Lymphocyte Subset (CD4+, CD8+) Counts Reflect the Severity of Infection and Predict the Clinical Outcomes in Patients with COVID-19. Journal of Infection. https://doi.org/10.1016/j.jinf.2020.03.054

[18] Charlson, M.E., Pompei, P., Ales, K.L. and MacKenzie, C.R. (1987) A New Method of Classifying Prognostic Comorbidity in Longitudinal Studies: Development and Validation. Journal of Chronic Diseases, 40, 373-383. https://doi.org/10.1016/0021-9681(87)90171-8

[19] Moreno, R., Vincent, J.L., Matos, R., Mendonça, A., Cantraine, F., Thijs, L., et al. (1999) The Use of Maximum SOFA Score to Quantify Organ Dysfunction/Failure in Intensive Care. Results of a Prospective, Multicentre Study. Intensive Care Medicine, 25, 686-696. https://doi.org/10.1007/s001340050931

[20] Wang, F., Nie, J., Wang, H., Zhao, Q., Xiong, Y., Deng, L., et al. (2020) Characteristics of Peripheral Lymphocyte Subset Alteration in COVID-19 Pneumonia. The Journal of Infectious Diseases, 221, 1762-1769. https://doi.org/10.1093/infdis/jiaa150

[21] Tay, M.Z., Poh, C.M., Rénia, L., MacAry, P.A. and Ng, L.F.P. (2020) The Trinity of COVID-19: Immunity, Inflammation and Intervention. Nature Reviews Immunology, 20, 363-374. https://doi.org/10.1038/s41577-020-0311-8

[22] Wan, S., Yi, Q., Fan, S., Lv, J., Zhang, X., Guo, L., et al. (2020) Relationships among Lymphocyte Subsets, Cytokines, and the Pulmonary Inflammation Index in Coronavirus (COVID-19) Infected Patients. British Journal of Haematology, 189, 428-437. https://doi.org/10.1111/bjh.16659

[23] Huang, I. and Pranata, R. (2020) Lymphopenia in Severe Coronavirus Disease-2019 (COVID-19): Systematic Review and Meta-Analysis. Journal of Intensive Care, 8 , 36. https://doi.org/10.1186/s40560-020-00453-4 